\title{
Service Innovation and TQM: A Conceptual Framework of Customer Satisfaction
}

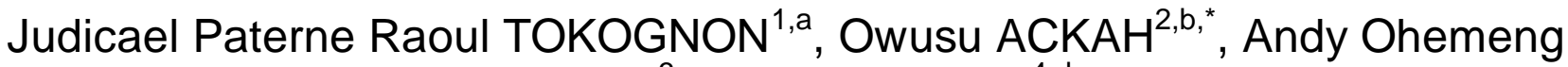 \\ ASARE $^{3, c}$, Yun-Fei SHAO ${ }^{4, d}$
}

School of Management and Economics, University of Electronic Science and Technology of China, No.2006, Xiyuan Ave, West Hi-Tech Zone, 611731, Chengdu, P.R. China

a19672898212@qq.com, backah_owusu@yahoo.com, 'andyohemengasare@yahoo.com,

dshaoyf@uestc.edu.com

${ }^{*}$ Corresponding author

Keywords: Service Innovation, Customer service satisfaction, Organizational performance, Quality management.

\begin{abstract}
Customer service plays an essential role in firm performance. In this perspective, customer service process should be constantly improved to meet the expectations of customers. Despite the essence of customer satisfaction and its relations to organizational performance firms still fails to satisfy its entire customer segments. This study examines how the interaction between service innovation and total quality management can contribute to customer satisfaction. The study proposes a framework that seeks to aid firms on how to develop and implement quality customer service for its customers. This model takes into consideration the perceived expectation of customers in relation to value and quality.
\end{abstract}

\section{Background of the study}

The rapid change in technology and customers demand for satisfied service over the past decades has evolved to affect how firms gain and retain customers in order to achieve sustainable growth and revenue. Therefore firms introduce various activities aided at customer satisfaction improvement [17;12]. Despite the abstract nature of service makes it complex to measure its quality on technical grounds [15]. Furthermore, the edge by firms to satisfy customers has lead to the integration of quality customer service management systems into the entire organization structure and activities [18]. This is evidence by the balloon in innovation expenditure in service organizations over the years [14]. This has resulted in an increase in research and development in a service context [9]. Firm that is able to harness these capabilities and resources turns to gain competitive advantage. Meanwhile, service innovation has received less scrutiny from the academic community and innovation scholars [16].

The demand for value added service from firms by customers has sharpen the mundus operandi of service organization, shifting to the provision of services that are perceived by customers to have value through the adoption of total quality management techniques and methods [11]. When customers' needs are satisfied in an expected manner, they turn out to become brand ambassadors for the firms through the interactions with other potential customers. This serves organizations with a large pool of potential customer base.

The purpose of this study is to examine service innovation and total quality management and how it can be employed to improve customer satisfaction. Furthermore, a customer satisfaction framework would be propose to aid the development of successful customer satisfaction strategies and polices among organizations.

This paper is structured as follows; the theoretical background that would serve as the bases for framework will be discussed in the next section, section three presents the customer satisfaction framework and its objectives used for this study. And the last section discusses the conclusion for this study. 


\section{Theoretical Framework}

Most firms in the service sector is affected by the disruptive theory proposed by Christensen et al (1996), therefore firms need to innovate in order to adapt their service to their customers expectation when that need arises. The changing demand of customers has being a source of innovation for new product and services of high quality and value [13]. Furthermore, the survival of any organization depends on the loyalty of its customers and this can be gain through provision of services that are perceived to be of high value and quality by customers. This aids firms to gain competitive advantage over its competitors. Despite firms want to satisfy customers need it should be done in conformity to accepted standards [8]. Therefore organization needs to integrate innovation into their service process to enable access to new markets that will serve as a new source of revenue generation. And this can be achieve the creation of value and improve service of high quality.

Meanwhile, despite the numerous advantages firms seek to drive from the introduction of innovation in their service delivery process, innovation is rare to the service industry. This can be attributed by the intangible nature of service and customers can also evaluate the value of service only when they have received it and this makes it difficult for firm to evaluate the factors that will satisfy customers [1]. In order to solve this impediment firms need to have an idea about the various kinds of markets and it competitors in the industry and also evolve its operations around a continuous value-added business model. Furthermore, firms need to create the environment that invites feedback from customer since customers are not only the source of creativity but also act as co-creators in the innovation process [3]. Therefore making the interaction between customer and organization an essential factor in service innovation [4]. The ability of firms to innovate in its service process continuous has empirically accepted to be related to an organizational performance in both large-small and medium enterprises [2]. Optimization is achieved through the exploration and exploitation of innovation process. When firm has a large market share and customer base it leads to a significant increase in its revenue and profit margins through the provision of services that satisfies customers' needs. When customers consume more of a product or service that is perceived to give value and meets customers expectations. Therefore firms not to understand the needs and value expectation of customers in order to innovate new improve services. The following preposition was formulated;

H1: Firms that have an interactive communication process with its customer gets to have in-depth understanding of customer value expectation and this contributes to an efficient service innovation process.

The dominance of service innovation as a medium for customer satisfaction can nit be achieved when is not toppled with quality management systems and techniques. This has being promoted by the rapid change of customers as to what service of high quality and provides the consumer more utility than other [5]. Therefore firms have the responsibility to find out what their customers expects in terms of quality. Total quality management is argued as an organizational requirement to balance its resources to meet the needs and expectations of customers. Customers can be satisfied through this process [6]. In implementation total quality management system and processes, there is the need to play critical attention to the feedback loop since it serve a platform for continuous interaction and development between customers and firms in the service innovation process. Furthermore, the introduction of quality management systems and techniques also help to reduce waste to its barest minimum thereby resulting into reductions in operational expenditures and time. This aids creates a standard benchmarks that serves as a reference point in standard evaluation [7].The interaction of total quality management and service innovation cannot be underestimated if organizations are able to satisfy customers needs. Firms can gain the trust and loyalty of customers for its brands though customer satisfaction and this as stated earlier is related to the financial performance of firms due to the competitive advantage gained and the large share of market that it enjoys. The following preposition was formulated;

P2: The continuous interaction between service innovation and total quality management will leads to the improvement of customer satisfaction. 


\section{Customer Satisfaction Framework and Motivation}

This section of the study presents the conceptual framework that is the focus of this study. With this framework proposed seeks to aid the improvement of customer service satisfaction through the creation of value by firms. According to this framework firms can create value through an interactive process between firms and customers to access their expectation in regards to value and quality. This approaches helps organization to have access to practical data and information from its potential customers and what they expects from contracting the services of a particular firm. During this process firms will have an idea about the dynamism of their customers and thereby tailoring service to meet the needs and expectations each market segment since all customers can not be satisfy through the introduction of any one particular service or strategy.

This is due to the fact that every customer has a different taste and behavior in relation to different services and products. Furthermore, the interactive nature of client-firm interaction provides a possible feedback loop that aids firms to have an evaluation of firm's service. This helps organizations to improve their service through continuous learning since innovation and for that matter service innovation is learning processes which need to be upgraded continuously to meet the specific and changing demands of customers within different aspects of the market segments. When services are provided to satisfy different customers, the organization thus retains and increases its market shares, while increasing revenue and growth.

This process furthermore enables firms to enrich their business innovation process that is a firm is able to improve continuously on its value creation process. Since customers patronize services that provides high value and utility. In order to understand what customer perceive as value can be determined through the reaction of the market or customers to a specific service, it can be a service from a rival firm or not. With the idea of customer reactions firms develop or innovate to meet their standards and value. If this is not adhered to it will lead to reduction in both sales and profits of firm. A value creation firm is a customer-retaining firm.

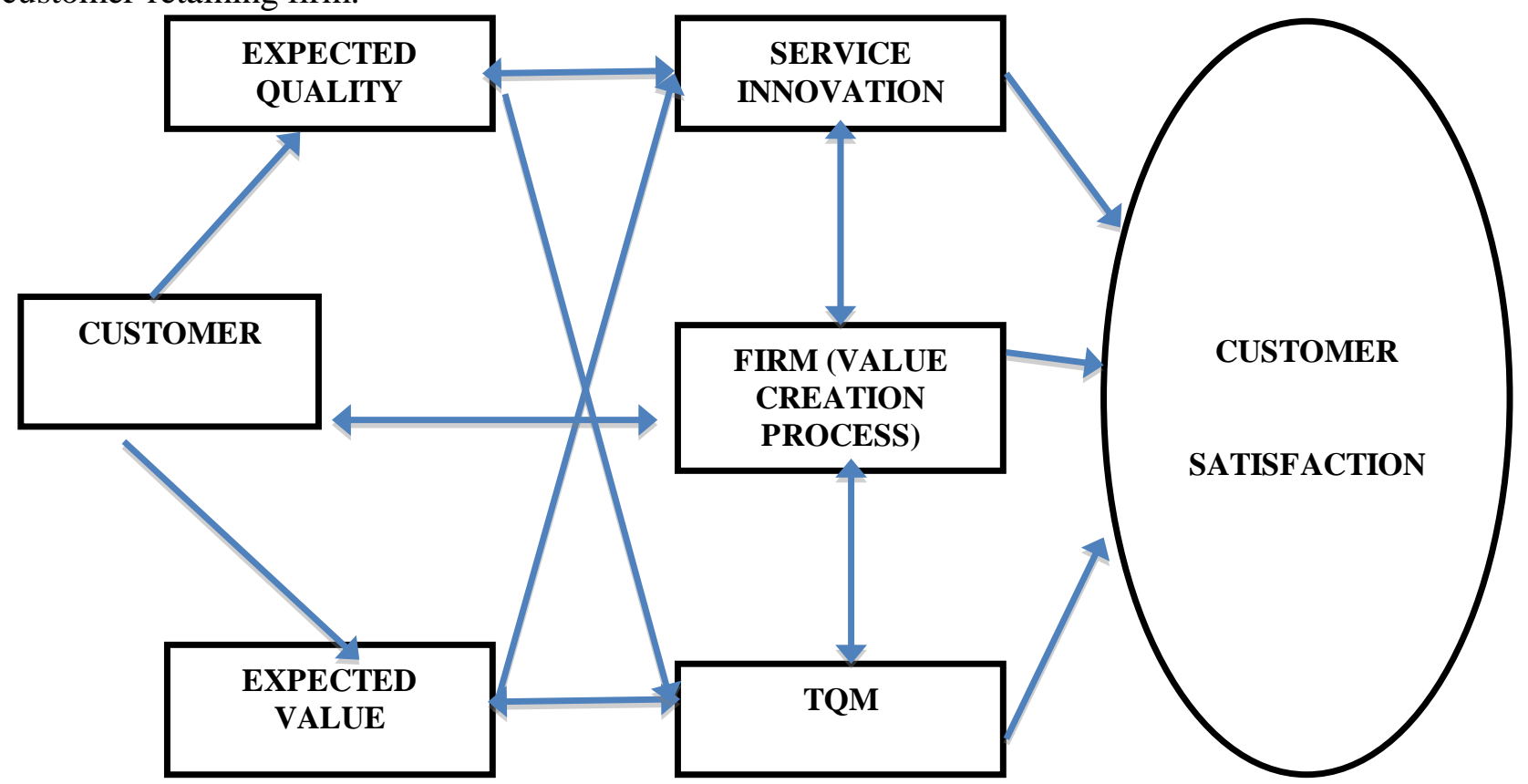

Figure 1. CSA model.

\section{Conclusion}

In recent times firms have being face with the challenge of an ever changing demand of customers due to change in technology, taste and consumer behavior. This has prompted firms to innovate in order to provide innovative-value added service to its clients so as to retain a large market share. Since satisfied 
customer turns to sticks to the firms with the firm that provides the kind of service that satisfy their individual needs.

This study proposed a conceptual framework upon which firms and organizations can attain customer satisfaction. This Customer-logic dominated model of service innovation proposed in this study is aim to aid firm achieve continuous learning and innovation through the frequent interaction between firms and potential customers.

Furthermore, service innovation within this context should be toppled with TQM systems and techniques in order to provide services that are of value and expected quality and standards. This will contribute to customer's satisfaction and improves organizations performance.

\section{Acknowledgement}

The researchers appreciate the support the University of Electronic Science and Technology of China and the School of Management and Economics have provided to enable the undertaking of this study.

\section{Reference}

[1] Berry, L., Shankar, V., Parish, J., 2006, Creating new markets through Service Innovation, MIT Sloan Management Review, Vol: 47, Issue 2, Pg. 56.

[2] Christopher M., McDermott, Daniel I. Prajogo, 2012, Service Innovation and Performance in SMEs, International Journal of Operation \& Production Management, Vol: 32, Issue 2, Pg. 216-237.

[3] Lusch, F., Vargo, S. L., Wessels, G., 2008, Toward a Conceptual foundation for service science: contribution from Service- dominant logic, IBM systems Journal, vol. 47, Issue 1.

[4] Liu, L. L., Chen, V. G., 2007, Service Innovation Mechanism based in customer-employee interaction, The 14th International Conference on Management Science and Engineering.

[5] Cesar Camunon, 1996, Total quality management in Hospitality: An application of the EFQM Model, Tourism Management, Vol. 17. Issue 3, Pg. 191-201.

[6] Smith, A. K., 1993, Total quality management in the Public Sector. Quality Process, Pg.45-48.

[7] Tewari, C. K., Dias, Shamit, 2010, Attaining excellence through total quality management in contemporary era, VSRD Technical \& non-technical Journal, vol. 1, Issue 1, Pg. 35-41.

[8] Hoyer, R. W., Hoyer B. K. Y., 2001, What is Quality? Quality Progress, Vol: 34, Issue 7, Pg. 52-57.

[9] Thomke, S., 2003, R \& D comes to success: Banks of America's pathbreaking Experiment. Havard Business Review, vol. 81, Issue 4, Pg. 70-79.

[10] Christensen, C. M., Bower, J. L., 1996, Customer Power, Strategic Investment, and the Failure of Leading Firms. Strategic Management Journal, vol. 17, Issue 3, Pg. 197-218.

[11] Nagaprasad, H., Yogesda, B., 2009., Enrischment of customer Satisfaction through total quality Management Technique Proceeding of the international multi-Conference of Engineers and Computer Scientist 2009, vol. 11, IMECS, March 18- 20, Hong Kong.

[12] Douglas, H., 2003. The moral responsibilities of scientists (tensions between autonomy and responsibility). American Philosophical Quarterly 40, 59-68.

[13] John Dimmick, Artemio Ramirez JR, Tao Wang, Shu-Fang Lin, 2007- Extending Society: the role of personal networks and gratification-utilities in the use of interactive communication media, New Media \& Society, vol.9 no.5 pp. 795-810.

[14] Tether, B. and Hipp, C., 2000,'Competition and innovation amongst knowledge intensive and other service firms: evidence from Germany' in Andersen, B., Howells, J., Hull, R., Miles, I. and Roberts, J. 
(Eds.) Knowledge and Innovation in the New Service Economy Edward Elgar, Cheltenham, UK and Brookfield, US.

[15] Bitran, G. R., \& Logo, M. 1993. A Framework for Analysing Service Operations. European Management Journal, 11(3): 271-282.

[16] Hilsenrath, J. E. 2003. The Economy: Service Sector Enjoys Growth, But Pace Slows, Wall Street Journal: A.2. New York, N.Y.

[17] Nauman, E., 1995, Creating Customer Value, Thompson Excutive Press, Cincinati, OH.

[18] Shemwell, D.J., Yavas, U. and Bilgin, Z., 1998, "Customer Service Provider Relationship: An Empirical Test of a Model of Service Quality, Satisfaction and Relationship-Oriented Outcome", International Journal of Service Industry Management, Vol.9, pp. 155-68. 